\title{
1 Attracting and retaining skilled and professional staff in remote locations of Australia
}

$2 \quad$ Fiona Haslam McKenzie

3 Graduate School of Business, Curtin University, 78 Murray St. Perth, WA, Australia

4 Email: f.mckenzie@curtin.edu.au

5

6 Abstract

7 Remote Australia constitutes approximately 75 per cent of the continent and is a dry, often

8 harsh environment in which to live; consequently less than three per cent of Australia's population reside there but it is also where a substantial proportion of Australia's export wealth is derived. It is therefore important that attention is paid to ensuring that remote locations in Australia are liveable and that innovative strategies are pursued to attract and retain a productive workforce in these places.

Attracting and retaining skilled and professional staff is a problem not limited to remote, or even rural and regional locations in Australia. There is strong evidence to suggest that it is increasingly a global problem and organisations throughout the world are seeking innovative strategies to attract and develop new talent and developing other strategies to retain that talent.

This paper examines population and labour mobility trends in remote Australia and the issues that have been influential on rates of staff attraction and retention, most particularly adequate housing, services and infrastructure. The second half of the paper examines a variety of recommendations and strategies developed by the public and private sectors to more effectively attract and retain skilled and professional staff to remote locations. This paper does not claim to be a rigorous analysis of all remote areas of Australia nor a comprehensive study of attraction and retention strategies. Rather, it aims to highlight the complexity, depth and interconnectedness of the issues for communities, public and private sectors and how they apply in remote locations in Australia.

Additional keywords: labour force, attraction, retention sustainable communities.

\section{Introduction}


Although approximately 75 per cent of Australia is dry and classified by the Australian Bureau of Statistics (2011a) as 'remote' or 'very remote', it is a highly urbanised country with about 75 per cent of the population living in a capital city (Australian Bureau of Statistics 2009b) and only three per cent of the population living in 'remote' or 'very remote' locations (Australian Bureau of Statistics 2010c). A large proportion of Australia's wealth is derived from the non-metropolitan areas, particularly the remote regions where mining activity dominates. A diversity of work is undertaken in remote, including desert, locations throughout Australia, employing an equally diverse labour force. Government administration, defence and mining have always been important industries and employers in the remote areas of Australia, but since 2001 mining and allied construction activities have escalated (Department of Infrastructure Transport Regional Development and Local Government 2009) in response to international market demand for Australian resources. The boom economic conditions have put extraordinary pressure on a highly sought-after skilled labour force and support services.

Settlement sizes in remote communities are varied, ranging from small Aboriginal Kalgoorlie. Across that range of communities there is also a broad assortment of business types and sizes. The mining towns in particular have experienced considerable growth pressures (Haslam McKenzie et al. 2009; Syme Marmion \& Co 2010), with demand for land suitable for residential and commercial development far exceeding supply. Despite industry and employment growth in remote regions over the last decade, the growth rate of taxpayer and household wealth in remote areas was generally lower than for the respective States (Australian Bureau of Statistics 2010a; Department of Infrastructure Transport Regional Development and Local Government 2009), notwithstanding the high labour force participation rates, indicating that a significant proportion of the increased employment is provided through fly-in/fly-out (FIFO) or drive-in/drive-out (DIDO) work arrangements. Government and private investment in infrastructure over the past decade have not kept pace with industry and employment growth, and consequently there is a high dependence on FIFO and to a lesser extent DIDO. Economic reasons and pragmatism appear to have been important motivators for companies and service providers to establish and then expand FIFO workstyle operations in the absence of functional towns (Storey 2001; Acil Tasman 2006; Haslam McKenzie 2011). The impact on FIFO workers, however, is less positive (Beach 
1999; Watts 2004; Gallegos 2005; Clifford 2009) with diminished work satisfaction, lifestyle and job tenure (Clifford 2009).

Many businesses and public-sector organisations throughout Australia find it difficult to attract, let alone retain, staff. This 'problem' is exacerbated in remote and desert Australia, which is far removed from the attractions of the cities as well as the comprehensive infrastructure and services that are available in high population centres. Reasons for the attraction and retention problems are complex. It is evident that the rapid turnover of professional and experienced staff can lead to a loss of knowledge of conditions, people, opportunities, needs, challenges and cultural differences in remote locations. This can cause significant economic, social and environmental costs and frustrations for all spheres of government and the private and public sectors.

Despite these 'push' factors that draw skilled and professional workers away from remote locations, there are well-documented 'pull' factors that could be utilised better to attract wellqualified people to live and work in isolated places. Based on comprehensive research undertaken for the Desert Knowledge Cooperative Research Centre (DKCRC), this paper will examine why the attraction and retention of skilled and professional staff to remote communities in Australia has been so challenging, even though there are significant social, professional and economic benefits and personal gains to be had from living in desert and remote Australian locations. A central concern of the research was how individuals and society fit together when people come together and live, work and socialise in a particular location and what the essential elements are of that place that make it attractive to people.

The research found that concern regarding the need to attract and retain skilled and professional staff to non-metropolitan areas of Australia is not a new dilemma and there have been successful strategies implemented. The successful attraction and retention initiatives were assessed by the research team for transferability and adaptability across a variety of remote and desert locations.

The paper begins by highlighting the challenges when trying to examine the socio-economic status of the remote areas of Australia. The task is made complex by a dearth of information in some cases, ambiguities regarding definitions of places and boundaries and, not unexpectedly, information and data gaps and overlaps. The following section examines population changes and mobility patterns in regional and remote areas of Australia in the last 
two decades, particularly in the current context where there are labour and key infrastructure shortages amid heightened industry activity. The paper then reports on a wide-ranging research project conducted on behalf of the Desert Knowledge Cooperative Research Centre which examined the pressing issues that recur throughout remote communities and their influence on staff attraction and retention, most particularly housing and infrastructure. The second half of the paper examines a variety of recommendations and strategies developed by the public and private sectors to more effectively attract and retain skilled and professional staff to remote locations. This paper does not claim to be a rigorous analysis of all remote areas of Australia nor a comprehensive study of attraction and retention strategies. Rather, it aims to highlight the complexity, depth and interconnectedness of the issues for community members, public and private sectors and how these issues apply in remote locations in Australia.

\section{Data collection, definitions and semantics}

The research project focused on gathering disparate sources of information and synthesising data and trends analyses regarding developing and maintaining a diverse work force in remote regions of Australia. A comprehensive review of the existing material used by both the private and public sectors to explore long-term attraction and retention solutions was undertaken. Specific data sources included the Australian Bureau of Statistics (ABS), mining company publications and government economic strategies and reports, as well as independent research from consulting companies, research students, private companies and public sector documents. An important phase of the research was visiting and speaking with local people who were living the remote and desert experience on a day-to-day basis. This was undertaken through face-to-face interviews and community focus groups. The intention was to be as participatory and inclusive as possible to determine the meso-, micro-, and macro-level understandings of skilled labour mobility and tenure.

There is a variety of ways of classifying sub-groups of the population who live outside the capital cities in Australia. The Census is the principal ABS statistical instrument that collects data for every geographical location in Australia. It uses definitions based on Australian Standard Geographical Classifications (ASGC) and throughout this document the same definitions have been used (Australian Bureau of Statistics 2011a). The Accessibility/Remoteness Index of Australia (ARIA) developed by the National Key Centre for Social Applications of Geographic Information Systems provides useful guidelines for 
this paper. The ARIA classifies localities by their 'remoteness', defined as the distance along road networks to service centres (a hierarchy of urban centres with a population of 5,000 people or more). The ABS has developed a Remoteness Structure based on the ARIA scores. Generally it is assumed that 'remote' is four hours' or more drive from an urban centre. 'Very remote' is usually more than four hours' drive from a range of services and is generally inaccessible by ordinary car. (This implies a non-bitumenised road.)

Semantics regarding remote and desert communities need to be mentioned here. A number of words throughout this paper are used interchangeably; for example, the words 'desert', 'outback' and 'remote'. The reason for this is that data are rarely collected for the 'desert' or the 'outback' regions but they are collected on the basis of the already discussed Accessibility/Remoteness Index of Australia. Based on the map in Fig. 1, the conditions described for remote communities generally coincide with the desert and outback conditions. Similarly, the word 'community' has different meanings for different people and agencies in various parts of non-metropolitan Australia. For some, 'a community' means a grouping of Aboriginal people living together in a small urban setting. In this paper, however, 'community' is used in the sociological sense; a community is a place where social institutions reside and social processes are generated between people (see Edgar 2001; Ife 1999).

\section{Place Figure 1 about here}

Similarly, the terms 'Outback' and 'desert' are not easily defined. Complex scientific definitions as well as colloquial references are used to describe them. Holmes (1997) has defined 'Outback' based on land uses and Stafford Smith et al. (2003) suggests that some characteristics are generally shared by all 'Outback' locations, while in other cases characteristics differ throughout the Remote and Very Remote 'Outback' regions. However, as identified by Stafford Smith et al. (2003) the common features are low population densities, high environmental variability, remoteness from markets and centres of power and a high proportion of Aboriginal people in the local populations.

'Desert' can be a nebulous description but the Desert Knowledge Cooperative Research Centre (Desert Knowledge Australia 2005) defined it as the areas that are arid or semi-arid, based on low rainfall levels and high evaporation with sparse vegetation. Guenther et al. (2005) provide a comprehensive précis of the Australian desert region. As shown in Fig. 1, 
the desert regions cover a large part of Australia. As the driest inhabited continent in the world, 69 per cent or 7.7 million $\mathrm{km}^{2}$ of Australia is classified as desert. These areas are naturally unlikely to support high numbers of human or animal populations due to unreliable water supply, although three per cent of the Australian population $(574,000$ people) live in desert Australia, many of whom are Aboriginal people living in as many as 1,300 discrete communities widely distributed across their traditional lands (Desert Knowledge Australia 2005). As a consequence, the distribution of goods and services across the region is patchy.

Developing an accurate picture of Australian rural, regional and remote population and labour market status is difficult because in the past, many of the ABS and Australian Bureau of Agriculture and Resource Economics (ABARE) statistical classifications are reported at a State-based, rather than small area (Statistical Sub-division or Local Government Area) level. The classification 'other urban' is a catchall label for rural, regional and remote categories that include small rural towns, larger rural centres and regional cities (Garnett and Lewis 2000).

Even more difficult to analyse are the definitions and measurements of change in the provision and maintenance of infrastructure and services, and there has been little research in these areas. Infrastructure expenditure by the Australian Federal Government has declined from 9 per cent of GDP in 1960 to about 4 per cent in 2004. In the two last decades, a dominant neo-liberal policy agenda has been the driving force of Australian government policy at all levels. Fiscal restraint by government is evident in contracting public expenditure budgets and the increased use of so-called market forces (Cheshire and Lawrence 2005), rather than government intervention, to drive change (Beer et al. 2005; Lawrence 2000). Policy decisions based on market forces put remote communities and regional centres at a considerable disadvantage because almost all of them have very small permanent population bases. Initiatives to attract and retain staff must consequently be creative and responsive to local conditions.

\section{Remote and non-remote population mobility}

The challenge of attracting and retaining populations in remote Australia has intensified over the last three decades with the shift towards a market-led allocation of resources and government policies that have encouraged rationalisation of services and devolution of services to regional and city centres. Over that time, there has been a continually declining 
population in numerous non-metropolitan locations (Haslam McKenzie and Stehlik 2005; Australian Bureau of Statistics 2009a), including many remote communities where mining or defence activities are absent. This is particularly evident in the youth cohort, both Aboriginal and non-Aboriginal, as many young people drift to cities for education, work and leisure and usually stay there (Biddle 2009). These are regularly cited 'pull' factors for young people from remote areas. An estimated one third of Aboriginal Australians live in capital cities and a further 43 per cent in regional areas (Australian Institute of Health and Welfare 2009). Further, while Aboriginal people outnumber non-Aboriginal people living in remote and very remote locations of Australia, census data show that the highest rate of Aboriginal mobility is from remote to semi-urban or major urban areas and there is a net deficit of people in remote locations (Australian Bureau of Statistics and Australian Institute of Health and Welfare 2008; Biddle 2009). The reasons why people move are myriad, but for Aboriginal people mobility is bound up with cultural practices as well as the practical need to access health and other services. Access to health and welfare services are consistent 'pull' factors, especially for older Aboriginal people. As noted earlier, there are remote and near-remote areas characterised by population growth, most particularly those areas where mining and resource extraction is operating (Australian Bureau of Statistics 2010b; Department of Infrastructure Transport Regional Development and Local Government 2009) but for the majority of remote settlements there is continual depopulation and/or influxes of transient populations from industries such as mining and tourism where the population increases are not sustainable or there is continual population churn.

Population churn comes at considerable cost to the social and economic fabric of communities. With the mining boom, many remote communities have been inundated by transient construction workforces. Transient populations put additional demands on communities because often they are not counted in the census (Meetham 2001; Murphy 2002; Yates et al. 2006). This has significant implications for local government, in particular regarding the distribution of Commonwealth grants, and means that local governments with mining and high FIFO activity are providing infrastructure and services for which they are not given resources commensurate with the resident and transient populations. A transient population often detracts from the long-term socio-economic viability of a community, and as a consequence communities are keen to develop strategies that will encourage longer tenure in remote and regional centres. Operational workforces are usually considerably smaller, imposing less strain on the infrastructure and community resources, but that does not 
necessarily mean they are permanent residents. While not all residents are community contributors, host communities, particularly small communities, generally believe that transient workers do not invest a sense of place and therefore do not contribute to local community organisations, participate in community building activities such as sporting groups or volunteering, and use community resources such as roads, utilities and other infrastructure with minimum return (Haslam McKenzie et al. 2009; Haslam McKenzie 2011). This puts unplanned and unresourced pressure on community leaders, especially the local government authority required to manage community development.

The high rate of labour force churn is linked, in part, to the strength of the local economy and labour shortages, resulting in competition for labour among mine-sites/companies. The problem has been exacerbated by poor planning by both the private and public sectors. In the past, mining companies have been loath to share corporate plans until public announcements were made to the stock exchange, claiming commercial confidentiality. On the government side, numerous reports have been written from the early 1970s highlighting inadequate infrastructure and housing for future growth and poor maintenance of the assets already on the ground (Government of Western Australia Department of Industrial Development 1974; Department of Planning and Urban Development 1992; Department of Housing and Regional Development 1994; Ministry for Planning 1997). Unfortunately, there has been minimal planning coordination across government jurisdictions and few of the recommendations in these reports were enacted by any level of government prior to the onset of the most recent resources boom. The lack of coordination and collaboration between industry and government in relation to the significant investment each is contributing to various initiatives throughout remote areas of Australia causes service and infrastructure gaps that take years to remediate. In particular, government's slow response to housing and land market signals (and hence, timely land release), has caused an escalation in housing and accommodation costs throughout Australian rural, regional and remote locations (Senate Select Committee on Housing Affordability in Australia 2008; Beer et al. 2011) but particularly in remote locations. As population trends have shifted, there is an increasing incidence of overcrowding, illegal sub-letting of accommodation and 'hotbedding' (Haslam McKenzie et al. 2009; Beer et al. 2011). The liveability of the affected communities is compromised as people move elsewhere where they have access to more affordable housing and/or a wider array of services. 
252 Since housing has such a significant impact on the distribution of wealth, housing characteristics and tenure types also affect the welfare of occupants (Haslam McKenzie et al. 2009; Tually et al. 2010). New development is stymied by the lack of a locally resident workforce and lack of accommodation for construction and other workers from outside the community (Johnson 2009). Cumulatively, the increased costs, particularly in communities where there is heightened mining activity, has caused the cost of living to escalate (Department of Local Government and Regional Development 2007). The Regional Prices Index has clearly shown that the cost of living in the Pilbara region in Western Australia, for example, is the highest in the State and far exceeds that of the capital city, Perth. While there are housing, general affordability and infrastructure issues in remote and regional towns which are not being addressed, the potential to facilitate long-term economic diversification is limited; thus, the opportunity to commute long distances from established, better resourced communities to remote sites is appealing.

Research (Salt 2006; Haslam McKenzie 2007; Zandvliet et al. 2008) suggests that some remote locations suffer from a poor reputation regarding future career opportunities, as well as often difficult living conditions for those who might otherwise be well qualified to work in the area and contribute significantly to the social, economic and environmental sustainability of remote, and in particular, desert locations. It is suspected that a contributing factor to these inefficiencies may be a paucity of awareness of the realities of remote and desert conditions, cultural misunderstanding of Aboriginal work practices and social needs, and limited understanding of the environmental challenges of remote locations.

Strategies for the attraction and retention of skilled and professional staff are therefore critical for the development of stable and diversified economies outside the metropolitan centres. The remainder of this paper examines innovative initiatives, including Aboriginal employment programs, developed by communities and companies to attract and retain staff and assesses their efficacy from socio-cultural, economic and environmental perspectives.

\section{Infrastructure and housing}

279 Remote and non-remote areas are highly dependent upon infrastructure networks (Zimmerman 2001). In remote areas, especially discrete Aboriginal communities, there is often a stark under-provision of basic infrastructure. The provision of critical services such as potable water, road networks and regular health checks can have significant impacts on the 
health and sustainability (physical and economic) of communities (Taylor 2006) Infrastructure provision in some remote areas is substandard and inadequate for sustainable human habitation (lack of potable water and health facilities, for example) (Haslam McKenzie et al. 2009).

As noted earlier, the rationalisation of infrastructure in remote areas is a significant challenge as infrastructure is interdependent on the existence of other forms of infrastructure. As an example, a nursing post is dependent on running water for hygiene and electricity to operate medical instruments. Removing one form of infrastructure will have an impact on other forms of infrastructure and, consequentially, on economic, social and environmental sustainability.

Pull factors such as the provision of adequate infrastructure facilities is often a deciding factor whether a non-Aboriginal family will stay in a remote community or move away, even if they are enjoying the community and the lifestyle offered to them in remote locations. This trend is particularly evident when children are reaching the end of their primary school education. Rural, regional and remote locations throughout Australia are constantly competing with city-centric infrastructure expectations. The provision of government infrastructure such as postal, health and education services, as well as corporate services such as banking are usually crucial for the survival of a viable community. Accessibility of essential services within an hour's travel is the accepted government standard but unreliability of the services and the lack of choice of service providers draws attention to the equity/efficiency trade-off (Gray and Lawrence 2001). Closely linked to the provision of key infrastructure is the need to attract and retain key workers (police, teachers, nurses and those who provide essential services). Not only do the income differentials between key workers and other employment sectors, especially mining, encourage key workers to move into other work, but also the provision of adequate housing for government and other service providers has slipped so that they are competing for not only housing, but casual accommodation. Government employee housing needs to be of a standard to ensure the attraction and retention of key human resources.

The size and footprint of the large mining companies, particularly during boom cycles, can have a significant and damaging effect on the local community's ability to access housing and staff for services and infrastructure. The companies have the much greater purchasing capacity and are able to secure a monopoly over hotel accommodation and housing, shutting out others in the community, making it very difficult for local businesses to attract and retain 
staff. The region quickly becomes a mono-economy, dominated by mining and associated activities as other less affluent industries such as retail, service, entertainment and childcare are marginalised. The impacts have been wide-ranging. Services normally expected in a functioning community are increasingly unavailable. For example, during site visits interviewees reported how they have had to drive 1,000 kilometres to Geraldton to have their car serviced by an approved garage or risk losing the warranty. The paint shop, IT service, dive shop, tourist operators, gift shop and mechanic shop had all closed in the regional mining town, citing the inability to attract and retain staff and/or excessively expensive commercial rents.

Despite the negative connotations associated with FIFO and DIDO work arrangements and mining companies more generally, they often provide or underwrite infrastructure in remote communities which would not otherwise be available. Arguing that they are paying substantial royalties to government, companies publicly resist calls to provide infrastructure and services that they see as being the responsibility of government or other sectors of society. Mining and resource companies have, however, shown a willingness to take a more pragmatic approach 'on the ground' and continue to be major infrastructure and service providers in some communities. In the Pilbara region for example, more than 470 dwellings were provided to government, local businesses, contractors and community groups by the major resource companies to ensure key workers and essential service workers are housed in the community. They have also provided sporting facilities and underwritten allied health services. Such interventions have mainly been driven by the need to attract and retain workers in a tight labour and housing market, rather than by abstract notions of corporate social responsibility.

The Western Australian government in particular has been criticised for the time lags in releasing suitable land for housing development and for the lack of key worker housing. Rather than retaining its own housing stock, government leases properties from the private market, exacerbating an already tight housing market (Senate Select Committee on Housing Affordability in Australia 2008). However, the Western Australian government, through the Royalties for Regions program (which quarantines 25 per cent of the State's mining and onshore petroleum royalties for additional investments in projects, infrastructure and community services in rural, regional and remote communities - over and above the State government service obligations), has released ambitious plans to revitalise towns in the State's north and build cities capable of housing at least 50,000 people and with amenities 
comparable to places such as Darwin and Cairns. The notion of 'liveability' appears to be a priority for the Pilbara Cities Blueprint, with a specific goal of attracting permanent residents, especially families, stimulating employment and jobs, and thus diversifying the local economy. Plans include more than 100 homes which will be quarantined specifically for service workers and rented at significantly lower than market rates. In the meantime, however, the government struggles to house key workers, and those who are not government employees must either pay unprecedented accommodation prices or move elsewhere.

Aboriginal housing is a critical and complicated attraction and retention issue for remote areas. Usually Aboriginal residents have a deeply embedded psychosocial and psychoenvironmental attachment to a locality in a way that Western society barely understands (Taylor 2002; Taylor and Kinfu 2005; Bell and Brown 2006). Neutze (2000) explains that the availability, affordability, suitability and tenure type of current Aboriginal housing is inextricably linked to rationalist market forces and government policies. While demand for appropriate Aboriginal housing exists, the process of requesting and occupying suitable houses is culturally different from the European model (Taylor 2002; Jones and Tonts 2003; Bell and Brown 2006; Haslam McKenzie et al. 2009). Aboriginal housing continues to be a contentious policy area, especially in remote communities, and to date has not been appropriately addressed.

\section{Strategies to enhance attraction and retention of staff in remote communities}

The strength of the economy, largely driven by the prolonged resources supercycle, was one of the main reasons why Australia avoided a recession during the recent global economic downturn (United Nations Development Program 2010; Australian Bureau of Statistics 2011b). Unemployment statistics have dropped and there is concern that Australia cannot meet skilled labour demand (Garton 2008; Chamber of Commerce and Industry Western Australia 2011). Not surprisingly, the sustained population growth has been principally from migration, a proportion of which has flowed to remote areas (Australian Bureau of Statistics 2010b). It is in the interests of all spheres of government, resource companies, service industries and the broader economy to develop strategies to ensure population retention strategies are effective to meet skilled labour demand and diversify local economies. As already noted, the cost of population churn, especially in small remote communities, can be high. Over and above the high cost of transporting, settling and integrating workers and their families to a community, there are considerable, often intangible costs, such as the disruption 
to services, the turnover in social networks such as sporting teams, clubs and social support groups and the need to develop local knowledge, understand local nuances and networks. At a local level community organisations, especially local government authorities, understand the potential personal and community costs associated with population churn and several have developed successful strategies to welcome workers and their families to ameliorate the sometimes uncomfortable settling-in process and so retain people in the community longer. It is important to note here, however, that it is fatuous to presume that strategies and initiatives are replicable or transferable across communities. No two communities or regions are alike and a 'one size fits all' response to attracting and retaining skilled and professional staff in remote Australia is naïve and unhelpful. That noted, the following initiatives have been successful and the resourcefulness and adaptive nature of the ideas may have potential for other similar enterprises and programs in remote communities.

Several local government authorities in remote areas of both New South Wales and the Northern Territory have worked with key worker organisations and service providers to assist them in developing local insights quickly, to counter the constant loss of community knowledge and intelligence. Mentors have been assigned to the newcomer, before they arrive in the community to establish a sense of familiarity and a point of contact. Interviewees reported this was effective in developing a better understanding about what to expect and, where necessary, how to better prepare for remote area living. An example has been the police service. Police services in remote areas have explored a number of different ways of implementing a mentoring program for officers new to remote areas. Perhaps the most successful has been a strategy where mentees have been paired with officers who have had experience in remote areas but not necessarily from the same State or Territory, thus minimising the potential for accusations of 'allegiances' or the transferral of 'reputations'. Police in small communities often struggle when living and socialising in close proximity to the same people they have to work with, or even police. Without adequate support and mentoring, roles, expectations and dilemmas can be enervating or worse, career shortening. In addition, police from urban areas do not always appreciate the different impacts of, and responses to, crime in remote areas. In remote communities with a high Aboriginal population, there are cultural considerations that need to be understood. Crimes with high degrees of associated guilt and shame (by both victim and perpetrator) may go unreported due to the large social impact that news of crime may have on local neighbours, friends and family. Some crimes, such as domestic violence and cultural retribution, the management of 
which requires coordination across multiple government departments, demand broad knowledge of the justice system overlaid with cultural sensitivities.

415 Husband and wife police teams are not uncommon which encourages retention in remote communities. However, the wife may be more exposed and vulnerable to drunken brawls and assaults in remote areas than in urban policing, and if she leaves, the community may lose two police officers rather than just one. Nonetheless, female police are valued for their communication skills, particularly with female community leaders, female victims of crime and in domestic violence events.

Distrust of police by Aboriginal people is common, and improved and targeted campaigns working with Aboriginal communities have been effective. It has been reported that police with a 'country background' have often gone to school with Aboriginal people. Some have entrenched prejudices while others have valuable insights to Aboriginal communities. These issues are not necessarily well understood by police agencies and need to be better addressed.

Police and law enforcement representatives interviewed for this research were concerned that the community inevitably viewed police as 'stick wielders' rather than potential 'community builders'. They were keen that communities understand their willingness to be role models and proactive social and community workers. It was their view that a consistent marketing campaign conveying positive messages about police and law enforcement workers in remote areas and the diversity of their work would assist with both attraction and retention of police in remote areas. Graeme Adcock, a Churchill Scholarship recipient in 2001/02, investigated non-metropolitan policing (Adcock 2002). His research found that good country policing and service revolve around excellent communication and negotiation skills. Adcock advocates a greater focus on problem-solving skills and key life skills and suggests this could result in improved retention of police officers in remote regions.

437 Within the public sector, there have been a number of strategies developed to enhance the remote area experience of employees and to better market remote communities. This has been achieved through newsletters and 'good news' stories in internal communications. In addition, in the Western Australian education sector, there has been a campaign to reward teachers through accelerated promotion for those who have worked in remote communities, recognising the social planning, service co-ordination and community development roles many teachers take on in isolated and often under-resourced communities. 
445 Commerce, the Broken Hill City Council and the Northern Territory Parks and Wildlife

446 Commission have all worked closely with Commonwealth and State-based agencies to attract

447 skilled and professional staff to remote areas. They have targeted specific skills sets and

448 demographic cohorts from overseas and tailored marketing programs, not only for the target

449 candidate, but also for the family members. In the case of the Goldfields Esperance

450 Development Commission, the age and interests of each family member are researched and

451 then a profile of local groups and clubs is provided in the hope of enthusing every family

452 member about a future move to the Goldfields region. As well, when the family arrives in the

453 region, arrangements are made to meet and greet the family and introduce each of them to

454 their respective interest groups. This initiative was used to introduce a medical doctor to the

455 region and this person and their family was subsequently successfully recruited.

456 Health services, or their lack, are often the difference between a person and their family

457 staying or leaving a region. The attraction and retention of medical and allied health staff in

458 remote and regional areas has been an ongoing problem for government, communities and

459 business for decades. Dunbabin and Levitt (2003) present evidence to show that the shortage

460 is not peculiar to Australia. Their international review of the phenomenon shows that

461 employing skilled and professional workers who have been raised in a remote location and/or have had previous experience in remote areas during training significantly increases the

likelihood of staff retention. There is also evidence to support the notion that the location of the educational institution determines the general area of practice. In Australia, there is a dearth of tertiary institutions located in non-metropolitan locations. Nonetheless, there have been some innovative initiatives developed to address the problem.

In South and Western Australia, Rural Health Scholarships are made available, and in some disciplines university entry requirements are lowered to attract candidates from rural, regional and remote backgrounds in the hope that they will return to those communities once they have qualified. In addition, there has been considerable investment in workforce and business planning with an emphasis on proactive strategies rather than continually reacting to workforce crises. Over the next five years there are plans to develop models that facilitate multiple health career pathways; explore and influence regulatory arrangements to facilitate required workforce supply and innovative solutions to workforce and workplace design; and actively target Aboriginal and other minority groups as potential health workers. To this end, positive relationships are being forged with the tertiary, education and training sectors to 
477 develop career pathways for rural students across a range of health disciplines. This is a tacit 478 recognition that employees with a non-metropolitan background already understand rural and remote communities and are likely to have an established affinity with them. As well, in both States, rural, regional and remote practicums are undertaken in non-metropolitan settings to develop improved understanding of communities, rural health opportunities and to 'mythbust' some of the poor images of rural job opportunities. This requires trainees to live and work in a location and has the added advantage of introducing them to the community which is increasingly focused on making health professionals welcome.

The Royal Flying Doctor Service (RFDS) in remote New South Wales has successfully pursued innovative strategies to counter high staff turnover and attract staff with a willingness to stay in a remote community and undertake an often challenging professional career. A focus on a primary health paradigm and the development of a university partnership resulted in attracting a different group of health professionals. The RFDS changed to a ruralbased focus rather than a transport service to the city, hence putting services back into remote areas. The RFDS has also targeted Australian doctors who have worked in Third World conditions with organisations such as Medicin Sans Frontier and Red Cross and understand third world health indices. Working in remote Australia provides many of the varied and challenging opportunities but without the often compromised political and other risks. The change in culture resulted in doctors who were well rounded and able to deal with emergencies, but had an interest in Aboriginal health and research. The Broken Hill RFDS has forged important links with the teaching hospital in the city providing health professionals with career progression opportunities and professional credibility. It also has generous leave-without-pay conditions for medical staff wanting to continue training and study. The organisation views this as an efficient practice; the corporate knowledge is not necessarily lost from the organisation and it takes less time to familiarise a previous employee with organisational practices than the time and commitment required to inculcate an entirely new recruit. Increasingly, regional service in remote New South Wales is no longer seen as a sign of failure for health professionals, but rather an experience that offers a variety of medical and emergency experiences and training.

Similar to general practitioners, mental health staff are sparsely distributed across remote Australian communities (Hodgins et al. 2004). Unlike poor physical health, mental illnesses can take longer to detect, and require regular visitation by the patient to their advisor. However, transport costs, high culturally based (unpredictable) mobility, low job satisfaction 
and high turnover of staff culminate in worsening health conditions. These detractors from community amenity create disincentives for medical staff to be attracted and retained in remote practices. Hodgins et al. (2004) suggest that training clinicians to detect specific mental illnesses in patients without relocating them to non-remote training colleges would be beneficial. Public, and increasingly private, health providers in all States are providing telehealth training and services. The advent and use of telehealth services has been important for ancillary medical assistance, and particularly important for training support and diagnosis and treatment of mental health issues in remote locations.

Another strategy being implemented in both the education and health sectors in Western Australia and South Australia is better preparation of recent graduates whose first job is in a remote location. Poor preparation of new graduates sent to non-metropolitan postings soon after graduation contributes to lack of understanding and the 'steep learning curve' that new staff face when moving to remote areas - especially those with a high density of Aboriginal people (Armitage and McMaster 2000), leading to poor performance in some cases or, often, staff turnover. For some graduates, the experience was so confronting they left before their first contract had been completed and they reported they were unlikely to engage with remote locations again. In some communities mentor or buddy systems have been improvised and generally they have had success in assisting retention rates. Mentor and buddy programs help to ease new recruits into the organisational culture of a remote organisation, introducing them into the community, and provide guidance about formal and informal networks that can so often be puzzling or even threatening for newcomers. This was deemed essential by interviewees who had worked in Aboriginal communities. Mentors assisted in newcomers gaining an understanding of the social operation of Aboriginal family and community arrangements relatively quickly, and without that informal 'teaching', misunderstandings and slights were common.

During the focus groups conducted for this research, it became clear that vocational training requirements and the schemes supporting vocational training differ in each State. This made it difficult for both employers and apprentices in places such as Broken Hill, which is serviced by vocational training organisations in Victoria, New South Wales and South Australia. It was reported that there was limited cooperation between the States, making it confusing and frustrating for employers and employees regarding training and assessment requirements. There was a clear need to improve integration of training needs and awards across State boundaries. Apprentices valued their institutional learning experiences for career 
support, friendships and culture (Dockery and Strathdee 2004). Both the employer and apprentice groups agreed that a strong work ethic and community support were very important for the attraction and retention of staff. Both groups also agreed that in an increasingly knowledge-based economy where career changes are frequent, the application of 'general' workplace skills is essential, most particularly basic numeracy and literacy skills.

Participation in remote economies is an important issue for Aboriginal communities. The Aboriginal population is rising (Australian Bureau of Statistics and Australian Institute of Health and Welfare 2008; Biddle and Yap 2010) and there is an increased expectation about the role that Aboriginal people will play in their local economies. In general, Aboriginal communities have a high proportion of young people who are dependent on welfare, detached from the labour market, and ill-equipped to engage in it. Daly and Hunter (1999) identify that casual and part-time employment with other Aboriginal people is often more attractive to Aboriginal workers than full-time employment with non-Aboriginal workers, and results in a greater retention of workers. The cohorts most dependent on social security were young, single Aboriginal people living in remote areas with characteristically low levels of education and extended periods out of the workforce. Moreover, the cost of job loss to Aboriginal people was higher than for the rest of the working population because, characteristically, their networks were less likely to have sufficient financial resources to support them during unemployment. Mining companies are increasingly targeting Aboriginal people for unskilled and semi-skilled work in remote communities. Of critical importance are basic numeracy and literacy skills and in some cases where these skills need to be upgraded in trainees, the companies will sponsor skills development. More frequently, however, the mining companies will work with, and contribute to, organisations such as the Graham (Polly) Farmer Foundation and Clontarf Aboriginal College, which support young Aboriginal people in education and training and provide culturally appropriate numeracy and literacy programs. The focus group discussion in a number of locations highlighted the potential opportunities associated with pre-apprenticeship and traineeship programs. These programs provide work experience, opportunities to work with local skilled employers and opportunities for employers to showcase their trade and the workplace options.

572 Throughout this project, there was concern raised by a variety of public sector workers that 573 they were financially compromised by remote country service. Adcock's (2002) research also highlighted this issue. He acknowledged that public sector workers remuneration was rarely 
going to be comparable to the private sector, and most particularly to the mining sector, but he did recommend several proposals, including taxation breaks similar to salary sacrificing. He argued that this would be useful for encouraging public sector officers whose partners might be concerned about the impact of a 'career break' due to country or remote location service. A taxation break would be advantageous for a family if one of the partners chooses to place their career on hold while the other partner undertakes country service, to be able to divert tax-free funds from the wage earner's salary to the non-wage earner's superannuation fund. A tax rebate, commonly referred to as the zone allowance or zone rebate, is paid in 'recognition of the disadvantages that taxpayers are subject to [in remote areas] because of the uncongenial climatic conditions, isolation and high costs of living in comparison to other areas of Australia' (Australian Taxation Office 2001). It comprises a base amount plus a percentage of other applicable rebates. It has been argued that the increases over time in the base amounts of the zone rebate have not been sufficient to offset the effect of inflation. More pertinent in the current labour market is the claim that the allowances do not sufficiently compensate families who must choose between the comforts and services available of a regional or urban setting and the relative discomforts and costs associated with living in a remote location. It was also vigorously argued by the National Rural Health Alliance (2006) in a submission to the Australian Taxation Office that the failure to update the base amount contributed to iniquitous conditions for those working in remote locations. 'The geographic application, structure and level of the rebates are thoroughly out of date. They should be modernised in the light of the government's intention to reduce the burden on taxpayers. If the beneficiaries of reform are to be those who are currently most heavily taxed, people in remote areas must be near the top of the list: but for the zone rebates, they pay the same rates of tax but have access to far fewer tax-funded services and facilities' (National Rural Health Alliance, 2006, p. 2). This contributes to economic and quality of life discrepancies by virtue of remoteness. The Henry Taxation Review (Henry 2010) considered changes to the rebate but no recommendations have been implemented that substantially change the value of the rebate or how it operates.

Adcock's (2002) research also suggested that international experience has shown that monetary incentives are important, but more meaningful, intrinsic rewards such as recognition in promotion and selection processes are more likely to encourage greater willingness and commitment to remote location service.

\section{Conclusion}


Attracting and retaining skilled and professional staff is a problem not limited to remote, or even rural and regional locations in Australia. There is strong evidence to suggest that it is increasingly a global problem and organisations throughout the world are seeking innovative strategies to attract and develop new talent and developing other strategies to retain that 612 talent.

613 Locations in remote areas have varied needs but there is the continual problem of attraction and retention, which is costing government and businesses time, money and lost opportunity. For the latter half of the last century, there has been a significant trend for population to shift to the large coastal urban centres, drawing young people to the cities, from where it is hard to lure them back. In addition, city-based workers usually have limited appreciation or understanding of work opportunities in remote locations and resist remote or regional service. This resistance is not unreasonable. Government policy has followed a stringent neo-liberal economic policy for the last three decades which has meant that services and infrastructure have been rationalised based on efficiency rather than equity. Currently, however, minority independent politicians who are aligned to rural, regional and remote communities and who understand their challenges currently hold the balance of power at the Federal level of government. They have been instrumental in directing large funds to non-metropolitan infrastructure and community-building projects. Similarly, the minority National Party in Western Australia holds the balance of power in that State and as part of the deal done to take government, the Liberal Party agreed to the Royalties for Regions initiative. These politicians have successfully argued that a significant proportion of Australia's export income is generated from remote communities and it is in everyone's interests to focus on the attraction and retention of skilled and professional staff to ensure there are viable, liveable and supportive communities. At a time when skilled migration is of critical importance and housing markets in Australian cities are tight, there are economic, if not social, benefits that will flow if remote communities successfully attract long-term residents.

This paper has reviewed a number of successful attraction and retention initiatives. They range in scope from public policy investments in better training and ensuring standards are consistent across State borders, to local community programs that work to make newcomers feel welcome or grow and nurture the people already living in remote locations. Corporate organisations also recognise that they have a role in properly preparing employees for remote service and that their presence can be both an advantage when there is local investment and increased commitment to local infrastructure, or a disadvantage when affluent corporates 
compete for housing and local labour, subsequently marginalising local businesses and people not employed in the corporate sector.

643 Many of the interventions reviewed in this paper are on a 'big picture' scale that is often 644 beyond the capacity of small dispersed remote communities and therefore require the understanding, commitment and leadership of government to spearhead. Health, education and to some extent housing are 'big ticket' government responsibilities and it is very important that their influence on the social viability of remote communities is understood. Remote Australia is a large and diverse space and no one place is like any other. Importantly, city-centric solutions are rarely viable and not appreciated. The participation of, and collaboration with, the community level is vital if innovative interventions and recommendations are to be actioned and meaningful.

It was found that lifestyle and a sense of community cannot be underestimated. A community with housing and infrastructure but no sense of community or social capital is likely to struggle to retain a workforce, whereas a remote community with a sense of place and inclusiveness but limited infrastructure will keep people for much longer. As noted by Gray and Lawrence (2001, p. 188) the challenge for regional Australia 'is not just to fix its social and economic policies, but rather to build socially, economically and environmentally strong communities which have the necessary linkages with global capital that extends beyond the short-term view'. The research documented here underscores the need to appreciate the interconnectedness of infrastructure, social functionality and economic efficacy to ensure a remote Australia that is indeed liveable and productive.

\section{Acknowledgements}

664 The work reported in this publication was supported by funding from the Australian

665 Government Cooperative Research Centres Programme through the Desert Knowledge Co-

666 operative Research Centre (2003-2010); the views expressed herein do not necessarily

667 represent the views of Desert Knowledge Co-operative Research Centre or its participants.

668 This research was conducted with the assistance of Dr Martin Bent, Ms Karen Smith and Mr

669 Christopher Jennings. Numerous local community leaders, residents, employees of 670 government agencies, community groups, area consultative committees, corporations and 
671

672

673

674

675

676

677

678

679

680

681

682

683

684

685

686

687

688

689

690

691

692

693

694

695

696

697

698

699

700

701

702

703

704

705

706

707

708

709

710

711

712

713

714

715

716

717

small businesses generously shared their information, expertise, insights, experiences and time.

\section{References}

Acil Tasman. (2006). Factors inhibiting industry development in the North West. In: Burrup Industries Forum. (Chambers of Commerce and Industry (Western Australia: Perth.)

Adcock, G. (2002). 'Country policing: Its not rocket science.' (The Winston Churchill Memorial Trust of Australia: Adelaide.)

Armitage, S., and McMaster, R. (2000). Rural and remote mental health placements for nursing students. Australian Journal of Rural Health 8, 175-179.

Australian Bureau of Statistics. (2009a). 'A Picture of the Nation.' (Cat. 2070.0). Australian Bureau of Statistics: Canberra.)

Australian Bureau of Statistics. (2009b). 'Regional Population Growth, Australia, 2008-09.' (Cat. 3218.0). (Australian Bureau of Statistics: Canberra.)

Australian Bureau of Statistics. (2010a). 'Australian National Accounts: National Income, Expenditure and Product.' (Australian Bureau of Statistics: Canberra.)

Australian Bureau of Statistics. (2010b). 'Regional Population Growth.' (Cat. 3218.0). (Australian Bureau of Statistics: Canberra.)

Australian Bureau of Statistics (2010c). Australian Standard Geographical Classification (ASGC) (Cat. 1216.0). (Australian Bureau of Statistics: Canberra).

Australian Bureau of Statistics. (2011a). 'Australian Standard Geographical Classification (ASGC)' (Cat. 1216.0). (Australian Bureau of Statistics: Canberra.)

Australian Bureau of Statistics. (2011b). 'Household income and income distribution, 2009-10.' (Cat. 6523.0). (Australian Bureau of Statistics: Canberra.)

Australian Bureau of Statistics (2003). 'Integrated Regional Database Australia' (Cat. 1353.0). (Australian Bureau of Statistics: Canberra).

Australian Bureau of Statistics, and Australian Institute of Health and Welfare. (2008). 'The Health and Welfare of Australia's Aboriginal and Torres Strait Islander Peoples.' (Canberra: Australian Institute of Health and Welfare.)

Australian Institute of Health and Welfare. (2009). 'Indigenous housing needs: A multi-measure needs model'. (Australian Institute of Health and Welfare: Canberra.)

Australian Taxation Office. (2001). 'Zone Rebates.' Available at: http://www.ato.gov.au/content.asp?doc=/content/ormsboa/rs_zo_zr.htm (accessed 1 May 2007).

Beach, R. (1999). The impact of intense work schedules on family structure: A case study of a 4:1 flyin/fly-out schedule in the Australian mining industry. In: 'Sociology for a New Millennium: Challenges and Prospects' (Ed. M. Collis, L. Munro and S. Russell) pp. 289-300. (CeLTS: Churchill.)

Beer, A., Clower, T., Haughton, G., and Maude, A. (2005). Neoliberalism and the institutions for regional development in Australia. Geographical Research 43 (1), 49-58.

Beer, A., Tually, S., Rowland, S., Haslam McKenzie, F., Schlapp, J., Birdsall-Jones, C., and Corunna, V. (2011). 'The drivers of supply and demand in Australia's rural and regional centres.' (Final Report \# 165). (Australian Housing and Urban Research Institute: Adelaide.)

Bell, M., and Brown, D. (2006). Who Are the Visitors? Characteristics of Temporary Movers in Australia. Population, Space and Place 12 (2): 77-92.

Biddle, N. 2009. 'The geography and demography of Indigenous migration: Insights for policy and planning.' (Centre for Aboriginal Economic Policy Research: Canberra.) 
Biddle, N., and Yap, M. (2010). 'Demographic and Socio-Economic Outcomes Across the Australian Indigenous Lifecourse.' (Centre for Aboriginal Economic Policy Research: ANU E-Press Canberra.

Chamber of Commerce and Industry Western Australia. (2011). 'Challenges hiding behind WA's rapid economic recovery.' Available at: http://www.cciwa.com/14_February_2011_1.aspx\#22922 (accessed 2 April 2011).

Cheshire, L., and Lawrence, G. (2005). Neoliberalism, individualisation and community: Regional restructuring in Australia. Social Identities 11, 435-445.

Clifford, S. (2009). 'The effects of fly-in/fly-out commute arrangements and extended working hours on the stress, lifestyle, relationship and health characteristics of Western Australian mining employees and their partners.' (University of Western Australia: Perth.)

Daly, A., and Hunter, B. (1999). Incentives to work: Replacement ratios and the cost of job loss among Aboriginal Australians. The Australian Economic Review 32, 109-124.

Department of Housing and Regional Development. (1994). 'Business investment and regional prosperity: The challenge of rejuvenation.' (Department of Housing and Regional Development: Canberra.)

Department of Infrastructure Transport Regional Development and Local Government. (2009). 'Northern Australia Statistical Compendium.' (Bureau of Infrastructure, Transport and Regional Economics: Canberra.)

Department of Local Government and Regional Development. (2007). 'Regional Price Index.' (Department of Local Government and Regional Development: Perth.)

Department of Planning and Urban Development. (1992). 'Pilbara 21: Final strategy report.' (Department of Planning and Urban Development: Perth.)

Desert Knowledge Australia. (2005). 'Facts about Desert Australia.' Available at: http://www.desertknowledge.com.au/dka/documents/Facts\%20about\%20Desert\%20Austra lia.pdf (accessed 8 June 2005).

Dockery, A. M., and Strathdee, R. (2004). 'Job finding methods of young people in Australia : An analysis of the Longitudinal Surveys of Australian Youth.' (Australian Council for Educational Research: Camberwell.)

Dunbabin, J., and Levitt, L. (2003). Rural origin and rural medical exposure: Their impact on the rural and remote medical workforce in Australia. Rural and Remote Health 3, 1-17.

Edgar, D. (2001). 'The Patchwork Nation : Re-thinking Government - Re-building Community.' (Harper Collins: Pymble.)

Gallegos, D. (2005). 'Aeroplanes always come back': Fly-in fly-out employment: managing the parenting transitions. (Centre for Social and Community Research, Murdoch University Perth.) Available at: www.meerilinga.org.au/upload/aeroplanes_always_come_back_final_report.pdf (accessed 28 August 2007).

Garnett, A., and Lewis, P. (2000). Population and labour movements in rural Australia. Australasian Journal of Regional Studies 6, 157-171.

Garton, P. (2008). 'The resources boom and the two speed economy.' (The Australian Government Treasury: Canberra.)

Government of Western Australia Department of Industrial Development. (1974). 'The Pilbara Study.' (Australian Government Publishing Service: Canberra.)

Gray, I., and Lawrence, G. (2001). 'A Future for Regional Australia: Escaping Global Misfortune.' (Cambridge University Press: Cambridge.)

Guenther, J., Young, M., Boyle, A., Schaber, E., and Richardson, J. (2005). 'Growing the desert: Regional and educational profiles of the Australian desert and its indigenous people.' Online 17th November 2005. (Desert Knowledge Cooperative Research Centre: Alice Springs.) Avasilable at: http://www.desertknowledge.com.au/file_store/66271A7F-C09F-44B0F1A0179C5E54A36D.pdf (accessed 8th August 2007) 
Haslam McKenzie, F. (2007). 'Attracting and Retaining Skilled and Professional Staff in Remote Locations.' (Desert Knowledge Co-operative Research Centre: Alice Springs.) Available at: http://www.desertknowledgecrc.com.au/publications/downloads/DKCRC-Report-21-StaffAttraction-and-Retention.pdf (accessed 6th June 2011)

Haslam McKenzie, F. (2011). Fly-in fly-out: The challenges of transient populations in rural landscapes. In: 'Demographic Change in Rural Landscapes: What Does it Mean for Society and the Environment?' (Ed. G. Luck, D. Race and R. Black) pp. 353-374. (Springer, Landscape Series: London.)

Haslam McKenzie, F., Rowley, S., Phillips, R., Birdsall-Jones, C., and Brereton, D. (2009). 'Housing Market Dynamics in Resource Boom Towns.' (Australian Housing and Urban Research Institute Perth.) Avilable at: www.ahuri.edu.au/publications/p80370/ (accessed $6^{\text {th }}$ June 2011)

Haslam McKenzie, F., and Stehlik, D. (2005). Futures for the Western Australian Wheatbelt - Is 2030 Already Here? Australian Journal of Agricultural Research 56, 1-15.

Henry, K. (2010). 'Australia's Future Taxation System.' Available at: http://www.taxreview.treasury.gov.au/content/FinalReport.aspx?doc=html/publications/pa pers/Final_Report (accessed 14 March 2011)

Hodgins, G., Murray, G., Donoghue, A., Judd, F., and Petts, A. (2004). Introducing a professional development programme to a rural area mental health service: The importance of context. Australasian Psychiatry 12, 153-160.

Holmes, J. (1997). Diversity and change in Australia's rangeland regions: Translating resource values into regional benefits. The Rangeland Journal 19, 3-35.

Ife, J. (1999). 'Community Development: Creating Community Alternatives - Vision, Analysis and Practice.' (Longman Frenchs Forest.)

Johnson, P. (2009). 'Fly-in fly-out and regional impact assessments.' (Regional Development Council Perth.)

Jones, R., and Tonts, M. (2003). Transition and Diversity in Rural Housing Provision: the case of Narrogin, Western Australia. Australian Geographer 34, 47-59.

Lawrence, G. (2000). International Landcare 2000 Conference, Global perspectives on rural communities: Trends and patterns. (Landcare, Australia: Melbourne.)

Meetham, K. (2001). 'Tourism in Global Society: Place, Culture, Consumption.' (Palgrave: Basingstoke.)

Ministry for Planning. (1997). 'Karratha land development program: Land release plan and infrastructure supplement.' (Ministry for Planning: Perth.)

Murphy, P. (2002). Sea change: Re-inventing rural and regional Australia. Transformations 2, 1-12.

National Rural Health Alliance. (2006). 'Overview of how Australia's Tax System Compares Internationally.' (National Rural Health Alliance: Canberra.)

Neutze, M. (2000). Housing for Indigenous Australians. Housing Studies 15, 485-504.

Salt, B. (2006). 'The Big Picture: Life, Work and Relationships in the 21st Century.' (Hardie Grant Books: Prahan.)

Senate Select Committee on Housing Affordability in Australia. (2008). 'A good house is hard to find: Housing affordability in Australia.' (Commonwealth of Australia: Canberra.) Available at: http://www.aph.gov.au/Senate/committee/hsaf_ctte/report/report.pdf (accessed 18 June 2008).

Stafford Smith, M., Walker, D., Maru, Y., Stoekl, N., Herr, A., Breen, J., and Greiner, R. (2003). 'Options for Understanding Regional Dynamics in Northern Australia.' Tropical Savannas CRC Project Report. (CSIRO: Alice Springs.)

Storey, K. (2001). Fly-in/Fly-out and Fly-over: mining and regional development in Western Australia. Australian Geographer 32. 133-148.

Syme Marmion \& Co. (2010). 'Extractive industry and sustainable regional develoment.' (Western Australian Regional Development Council: Perth.) 
Taylor, J. (2002). 'Population Futures in the Australian Desert 2001-2016.' Discussion Paper 231/2002). (Centre for Australian Aboriginal Economic Policy Research, Australian National University: Canberra.)

Taylor, J. (2006). 'Indigenous people in the West Kimberley labour market.' Working paper 35/2006. (Centre for Aboriginal Economic Policy Research: Canberra.)

Taylor, J., and Kinfu, Y. (2005). 'Determinants of Indigenous population mobility: Insights from the NATSISS.' (Centre of Aboriginal Economic Policy Research: Canberra.)

Tually, S., Beer, A., Rowley, S.,Haslam McKenzie, F., and Birdsall-Jones, C. (2010). 'The drivers of supply and demand in Australia's rural and regional centres.' Positioning Paper \#128. (Australian Housing and Urban Research Institute: Melbourne.)

United Nations Development Program. (2010). 'Curse or blessing? Natural Resources and human development.' (United Nations: New York.)

Watts, J. (2004). 'Best of Both Worlds: Seeking a Sustainable Regional Employment Solution to Fly In - Fly Out Operations in the Pilbara.' (Pilbara Regional Council: Karratha.)

Yates, J., Randolph, W., and Holloway, D. (2006). 'Housing affordability, occupation and location in Australian cities and regions.' (AHURI: Sydney.)

Zandvliet, R., Bertolini, L., and Dijst, M. (2008). Towards planning for a mobile society: Mobile and residential populations and the performance of places. European Planning Studies 16, 14591472.

Zimmermann, R. (2001). Social implications of infrastructure network interactions. Journal of Urban Technology 8. 97-119. 
844 Fig. 1. Extent of Arid Zone (Desert Region) used in analysis by 2001 ASGC

845

846 Source: Taylor (2002) and ABS (2003) in Guenther et al. (2005) 